\title{
Implementasi peranan wanita dalam konteks gereja di toraja pada masa kini
}

evriyani lambang mandi'

eriyanilambangmandi@gmail.com

\begin{abstract}
Abstrak
Melihat dari kisah penciptaan dapat dikatakan bahwa kesetaraan gender sudah di tentukan menurut ukuran Allah sendiri "kejadian 1:26 berfirmanlah Allah : "baiklah kita menjadikan manusia..." nas ini merujuk pada pemahaman bahwa laki-laki dan perempuan memiliki kesetaraan yang sama, kendatipun telah jatuh kedalam dosa namun manusia dituntut untuk berada pada tempat dan peranan mereka sekalipun dalam praktek masa kini masih saja terdapat perbedaan gender yang terjadi. Makalah/paper ini memfokuskan pembahasan ke arah implementasi peranan wanita dalam gereja dan peranan wanita dalam alkitab dengan merujuk kepada dua wanita dalam PL dan PB.
\end{abstract}

Kata kunci: implementasi, pernanan wanita, toraja

abstract

Seeing from the creation story, it can be said that gender equality has been determined according to God's own standards "Genesis 1:26 God said: "Let us make humans..." This passage refers to the understanding that men and women have the same equality, even though they have fallen. into sin but humans are required to be in their place and role even though in today's practice there are still gender differences that occur. This paper focuses on the implementation of the role of women in the church and the role of women in the Bible by referring to the two women in the OT and NT.

Keywords : implementation, the role of women, toraja 


\section{Pendahuluan}

Apakah kedudukan atau peranan wanita dalam gereja pada masa lalu dan masa kini? Mungkin ini merupakan pertanyaan yang biasa-biasa saja, tetapi jika kita mendalami pertanyaan ini, maka kita akan menyadari bahwa ternyata gereja pada masa lalu tidak terlalu memperhatikan keberadaan wanita. Tetapi, karena kemajuan zaman dan pengetahuan maka gereja mulai mengalami perubahan dan kesetaraan gender mulai diterapkan seperti dalam konteks gereja yang ada di toraja saat ini, dimana gereja-gereja tidak lagi hanya menfokuskan laki-laki sebagai yang paling utama dalam pelayanan dan mensejajarkannya dengan peranan wanita kendatipun dalam prakteknya masih samar - samar. Kesepadan gender yang asli mulai rusak Ketika manusia jatuh ke dalam dosa. Dalam kitab kejadian 3:1-24 menjelaskan tentang tanggung jawab setiap laki-laki dan perempuan.

\section{Tujuan dan Manfaat}

Tujuan dari penulisan makalah/paper ini adalah untuk mengetahui peranan wanita dalam alkitab baik dari PL dan PB dan peranan wanita masa kini dalam konteks gereja secara umum dan gereja di toraja dan di harapkan dapat bermanfaat bagi pertumbuhan pengetahuan kita mengenai peranan wanita. 


\section{PEMBAHASAN}

A.Pengertian implementasi secara umum dan dalam konteks toraja serta pengertian wanita

Implementasi menurut KBBI adalah pelaksanaan, penerapan. Implementasi ialah kegiatan yang dilakukan dengan perencanaan dan mengacu kepada aturan tertentu untuk mencapai tujuan suatu kegiatan. Implementasi dapat diartikan sebagai sesuatu yang sedang dilaksanakan. ${ }^{1}$ Implementasi berarti pelaksanaan atau pengembangan untuk mencapai tujuan dari suatu kegiatan yang dapat di salurkan melalui ide, kecendekiaan yang nyata agar dapat membawa transmutasi atau pengembangan.

Peradaban manusia Toraja sudah ada jauh hari sebelum datangnya institusi sekolah. Mereka tumbuh dan berkembang secara tradisional, dengan norma dan tatanan sosial yang melahirkan entitas budaya serta identitasnya ${ }^{2}$. Dalam konteks toraja, implementasi atau pengembangan dimulai sebelum mereka mengenal dunia Pendidikan, namun walaupun mereka demikian, mereka telah belajar mengenai aturan serta tatanan social yang kemudian melahirkan budaya, kearfikan local serta asal usul toraja. Salah satu bukti dari implementasi orang-orang toraja adalah rumah adat "banua tongkonan". Kendatipun tongkonan dipahami parsial dan dangkal yakni sekadar bangunan rumah tradisional saja, namun pasang surut berbudaya mereka ini menarik untuk dicari tahu, hingga bisa membentuk satu entitas budaya lokal yang perennial. Tanpa pengajaran institusioal formal, namun secara dinamis orang Toraja bisa bertumbuh dalam karakter luhur, sangup beradaptasi dan bertahan di tengah

\footnotetext{
${ }^{1}$ https://www.poskata.com/arti/implementasi, diakses pada tanggal 7 desember 2021, pukul 00:03.

2 Rannu Sanderan, "Heuristika dalam Pendidikan karakter manusia toraja tradisional", jurnal teologi dan Pendidikan Kristen kontekstual, (Toraja utara, Available at: http://www.jurnalbia.com/index.php/bia,2020), hal 306.
} 
pengaruh identitas budaya baru. ${ }^{3}$ Walaupun kadang rumah tongkonan dipandang sebelah mata oleh orang, namun dalam konteks masa kini gereja memakai rumah tongkonan sebagai lambing atau symbol karena tongkonan itu sendiri bermakan rumah persatuan "banua pa'rapuan" dan dengan demikian di toraja menampakkan keberadaan toraja di tengah-tengah gereja.

Secara etimologi, kata perempuan berasal dari kata етри dalam Bahasa jawa kuno, yang kemudian diserap dalam Bahasa melayu yang berarti "tuan, mulia, hormat". Kata empu tersebut mengalami pengimbuhan dengan penambahan "per dan an" yang kemudian membentuk kata "perempuan". Kata wanita berasal dari kata vanita dalam Bahasa sansekerta yang secara harafiah berarti yang "diinginkan". ${ }^{4}$ Jadi, wanita atau perempuan adalah makhluk ciptaan Allah yang terhormat dan yang diinginkan. Wanita merupakan makhluk yang memiliki peranan yang sangat besar dalam proses implementasi. Seperti tokoh dalam alkitab yaitu hawa yang permulaannya melakukan implementasi menururt kehendak Allah setelah manusia jatuh ke dalam dosa, kejadian 4:1-26.

Pembedaan tanggung jawab antara laki-laki dengan perempuan nampak mulai timpang tatkala manusia jatuh ke dalam dosa. ${ }^{5}$ Dapat dikatakan bahwa dari awal kejatuhan manusia ke dalam dosa telah mengakibatkan pembedaan antara laki-laki dan perempuan dalam segi tanggung jawab, dimana laki-laki lebih ditonjolkan atau dominan dalam segala hal sedangkan perempuan ditundukkan dan hal itu berlaku bagi gereja pada masa lalu tetapi tidak lagi bagi gereja masa kini dengan melihat realitas kehidupan gereja di toraja.

B.peran wanita dalam alkitab

a) Peran wanita dalam PL

Di dalam PL, ada seorang perempuan yang sebernarnya bukan berasal dari keturunan perjanjian namun ia dipakai Allah untuk mejadi penerus silsilah dari Yesus Kristus, dia adalah ruth. Kitab ruth sendiri merupakan kitab sejarah pada PL yang mengisahkan tentang peranan seorang wanita dalam silsilah keturunan Yesus. Kitab Ruth dituliskan agar menguraikan apa itu kasih yang berkorban dan pelaksanaan hukum dari Allah dengan benar dan menceritakan tentang seorang wanita yang taat dan saleh. Dengan rencana Allah, ruth menikah dengan boas dimana dalam hal ini merupakan catatan anti

\footnotetext{
${ }^{3}$ Rannu Sanderan, "Heuristika dalam Pendidikan karakter manusia toraja tradisional", jurnal teologi dan Pendidikan Kristen kontekstual, (Toraja utara, Available at: http://www.jurnalbia.com/index.php/bia,2020), hal 307.

${ }^{4}$ https://id.m.wikipedia.org/wiki/perempuan, di akses pada tanggal 7 desember 2021, pukul 21:46.

${ }_{5}^{5}$ Rannu sanderan, "jabatan gerejawi dan peranan perempuan dalam pelayanan gereja” (Toraja Utara), hal.1
} 
separatis yang ditulis untuk melawan sikap keras ezra dan nehemia dalam menentang perkawinan campuran. Boas yang kemudian mengambil ruth sebagai istrinya setelah melewati scenario yang cukup menarik. Dimana naomi yang adalah ibu mertua dari ruth turut ambil andil dalam mempersatukan mereka. Kendati pun ruth berasal dari moab, bangsa yang tidak mengenal Allah tetapi Allah merencanakan suatu peranan yang sangat besar dan indah bagi dirinya dan hal ini dapat dikatakan sebagai pembuka jalan bagi non-yahudi untuk menjadi bagian dari keluarga Allah. Dari keturunan ruth dan boaslah lahir silsilah kelahiran sang Raja yang telah di janjikan yaitu Yesus Kristus. Implikasi teologis yang dapat diperoleh adalah bahwa ada pelajaran penting dari kisah Rut yakni tentang kesetiaan dan kasih Rut kepada ibu mertuanya, Naomi. ${ }^{6}$

b) Peran wanita dalam PB

Di dalam PB, peranan wanita yang juga di pakai Allah dalam rencana penyelematan melalui Si Gondrong "Yesus Kristus" adalah maria. Maria memiliki peranan yang sangat mulia dan wanita pilihan Allah yang sangat diperkenankan yang menjadi Ibu dari Yesus Kristus dan karena menjadi wanita pilihan, maka maria memiliki tanggung jawab yang sangat besar dan tantangan yang besar. Ketika Yusuf mengetahui kehamilannya, ia kemudian ingin menceraikannya, namun kendatipun demikian Allah tetap menyertai maria karena imannya yang kuat. Peranan maria jika dipikirkan secara rasional pasti orang yang sanggup melakukan hal tersebut adalah orang yang memiliki kedalaman iman dan keyakinan penuh pada YAHWEH Allah seperti yang telah di perankan oleh maria. Peranan maria yaitu sebagai sarana keselamatan Allah. Mungkin akan banyak asumsi bahwa bagaiaman bisa seseorang melahirkan tanpa melalukan hubungan dengan lawan gender? Namun pertanyaan itu perlu kita banta bahwa tidak ada yang bisa menyelami akan kuasa Allah. Maria sebagai bunda Allah dan bunda gereja, yang mengacu pada keikhlasannya untuk menerima kehendak Allah.

C. perwujudan peranan wanita sebagai wujud implementasi dalam konteks gereja pada masa kini

Peran wanita pada masa kini, bukannlah suatu yang tabu untuk dibicarakan, sangat banyak wanita yang berperan dalam berbagai bidang, misalnya : gereja,keluarga,organisasi

\footnotetext{
${ }^{6}$ Rannu Sanderan dan Yohanes Krismantyo Susanta, "pemahaman tentang sayap dalam kitab ruth: studi kritik naratif", kamasean : jurnal teologi Kristen, (institute agama Kristen negeri toraja, Available at:http://kamasean.iakn-toraja.ac.id, 2021), hal 57
} 
pemerintahan, dan lain-lain. Namun pada konteks gereja, ternyata masih ada gereja yang belum memakai perempuan dikarena mereka masih menerapkan budaya patriaki maskulin kendatipun demikian, dalam konteks gereja toraja saat ini, perempuan telah diberdayakan sekalipun masih ada batas yang biasa menomorkan duakan wanita dalam gereja. Dalam kejadian 1:26-28, menjelaskan tentang kebenaran fundamental mengenai manusia karena pada dasarnya manusia diciptakan segambar dan serupa dengan Allah, dan bahwa laki-laki harus sepadan dengan lakilaki.

\section{A.Kesimpulan}

Peranan wanita dalam gereja pada masa kini memiliki peranan yang memiliki beberapa pemahaman yang berbeda baik dalam segi pelayanan maupun dalam memimpin sebuah organisasi gerejawi. Menurut Emanuel gerrit singgih di dalam implikasi gender dalam Lembaga Pendidikan teologi yang dikutip oleh elkana chirsna Wijaya, mengatakan bahwa kemajuan dan keterlibatan wanita berlum terlalu signifikan dan belum menggembirakan. Kurangnya partisipasi wanita karena perbedaan gender disebabkan karena anggapan bahwa wanita tidak pantas menempati posisi tersebut. Tetapi terlepas dari itu, di gereja toraja saat ini, sudah mulai menerapkan persamaan gender dalam gereja maupun organisasi gerejawi sekalipun masih di bayang-bayangi oleh keinginan perbedaan status gender.

B.Saran

Penyusunan makalah/paper ini sangat jauh dari kesempurnaan oleh karena itu penulis menerima setiap kritikan dan saran dari segenap pembaca.

\section{DAFTAR ISI}

Sanderan Rannu, 2020, "Heuristika dalam Pendidikan Karakter Manusia Toraja Tradisional”, jurnal teologi dan Pendidikan Kristen kontekstual Volume 3, No2, (halaman 306-307), Toraja utara: Available at: http://www.jurnalbia.com/index.php/bia.

Sanderan Rannu, "jabatan gerejawi dan peran perempuan dalam pelayanan gereja", Toraja utara: hal 1.

Sanderan Rannu dan Susanta Yohanes Krismantyo, "pemahaman tentang sayap dalam kitab rut :studi kritik naratif", kamasean : jurnal teologi Kristen volume 2, no 1, (halaman 57), institute agama Kristen negeri toraja : Available at:http://kamasean.iakn-toraja.ac.id. 
https://www.poskata.com/arti/implementasi, diakses pada tanggal 7 desember 2021,pukul 00:03.

https://id.m.wikipedia.org/wiki/perempuan, di akses pada tanggal 7 desember 2021, pukul 21:46. 